\title{
Study of Grid Connected Wind Energy System with Fuzzy Logic Based Mppt Controller
}

\author{
Jayalakshmi N. S., Sachin S. \\ Department of E\&E Engg., Manipal Institute of Technology, Manipal Academy of Higher Education, \\ Manipal 576104, India
}

\begin{tabular}{l}
\hline \hline Article Info \\
\hline Article history: \\
Received Jun 12th, 201x \\
Revised Aug 20th, 201x \\
Accepted Aug 26th, 201x
\end{tabular}

\section{Keyword:}

Fuzzy logic controler MPPT, perturb and observe (P\&O)

PMSG

Wind energy

\section{Corresponding Author:}

Jayalakshmi N. S.,

Department of E\&E Engg., Manipal Institute of Technology,

Manipal Academy of Higher Education,

Manipal, India-576104.

jayalakshmi.ns@manipal.edu

\begin{abstract}
Renewable energy sources (RESs) are gaining more importance due to depleting fossil fuel sources in few decades. When compared to other RESs wind energy system is widely available and user friendly in nature. This paper presents modelling and simulation of grid connected PMSG based wind energy conversion system with $\mathrm{P} \& \mathrm{O}$ maximum power point tracking (MPPT) control technique. The PQ controller is used for grid tied inverter to exchange real and reactive power with DC bus voltage regulation. The fuzzy logic controller (FLC) is used for MPPT implementation as it provides better performance as compared to the traditional PID controllers. The various case studies are considered for power management between wind system and the utility grid and the results are evaluated in MATLAB/Simulink platform.
\end{abstract}

Copyright (c) 2018 Institute of Advanced Engineering and Science. All rights reserved.

\section{INTRODUCTION}

The usage of distributed renewable energy resources has been increasing to reduce the pollution, to increase network reliability and it facilitates the electrification in case of remote areas. At present scenario, fossil fuel resources are the major energy sources for providing the load demand. With the depletion of conventional resources and growing concern towards clean atmosphere, renewable or alternate sources of energy are drawing more attention worldwide to compensate the growing energy demand. Among all RESs wind energy is the most prominent and clean energy source which is widely available all over the world. Furthermore, 52GW of clean and emissions-free wind power was installed in 2017, bringing 539 GW of total installations globally and it has been increasing in the last few years [1].

The modelling and control of wind energy conversion system (WECS) and permanent magnet synchronous generator (PMSG) is used in the system due its high power density and efficiency as compared to other electrical generators. The PMSG is a best choice for variable wind speed turbine since it is directly connected to the turbine without gear box and it does not require additional excitation. The detailed mathematical modelling of a wind turbine driven by a PMSG is proposed in [2]. The performance and control strategy of grid coupled PMSG based wind system is analysed in [3]. The details of modelling of wind turbine with PMSG and MPPT control scheme is discussed in [4].

The most popular applications with wind turbines have been increasing due to a significant growth of power electronics and improved MPPT techniques to extract the maximum power from variable wind speed. The various MPPT techniques are proposed in [5, 6]. Among the existing techniques, the most widely used one is perturb and observe algorithm (P\&O) which is analysed in [7-9]. To get maximum power from the wind generating system, the MPPT control technique is needed. The P\&O method is designed using a 
boost converter and a controller in order to extract maximum power depending on the reference rotor speed generated by the algorithm. The FLC is used for controlling reactive power due to its higher efficiency compared to other controller which has been investigated in $[10,11]$. The modeling and control techniques of FLC based inverter system for grid connected wind generator is reported in [12]. The PQ control strategy is used for controlling 3-phase inverter [13-15]. It helps in regulating the active and reactive power exchange between the wind system and utility grid and it helps in maintaining the DC link voltage.

In this paper, the operation of WECS is discussed in detail under varying conditions of wind velocity and load demand. The grid integrated WECS consists of uncontrolled rectifier, boost converter with MPPT controller with minimum switching losses with controlled 3-phase inverter. The MPPT control technique is realized using conventional PID controller and FLC based controller to regulate the speed of PMSG rotor in order to yield the maximum power from WECS. The error and change in error are given as an input to FLC to regulate the speed of rotor as per the reference speed. The Fuzzy logic algorithm is used to minimize the error between the actual power and the estimated maximum power. The paper is arranged as follows. The section 2 describes wind energy system configuration. The section 3 discusses modelling and control strategies. The section 4 presents results with discussions and the conclusions are reported in section 5 .

\section{SYSTEM CONFIGURATION}

The schematic diagram of grid connected wind power system configuration is depicted in Figure 1. The wind system has a PMSG driven by a wind turbine of $20 \mathrm{~kW}$ capacities, a non-controlled bridge rectifier and a boost converter with MPPT controller for tracking the maximum power. The results are compared both with conventional PID controller and FLC based MPPT controller to regulate the speed of PMSG rotor to get the maximum power. The Fuzzy logic algorithm is implemented to minimize the error between the actual power and the estimated maximum power. Three-phase inverter with PQ controller and R-L filter is used for interfacing WECS to the utility grid. The grid side inverter is responsible to keep the DC link voltage constant during variation in source power and the load demand.

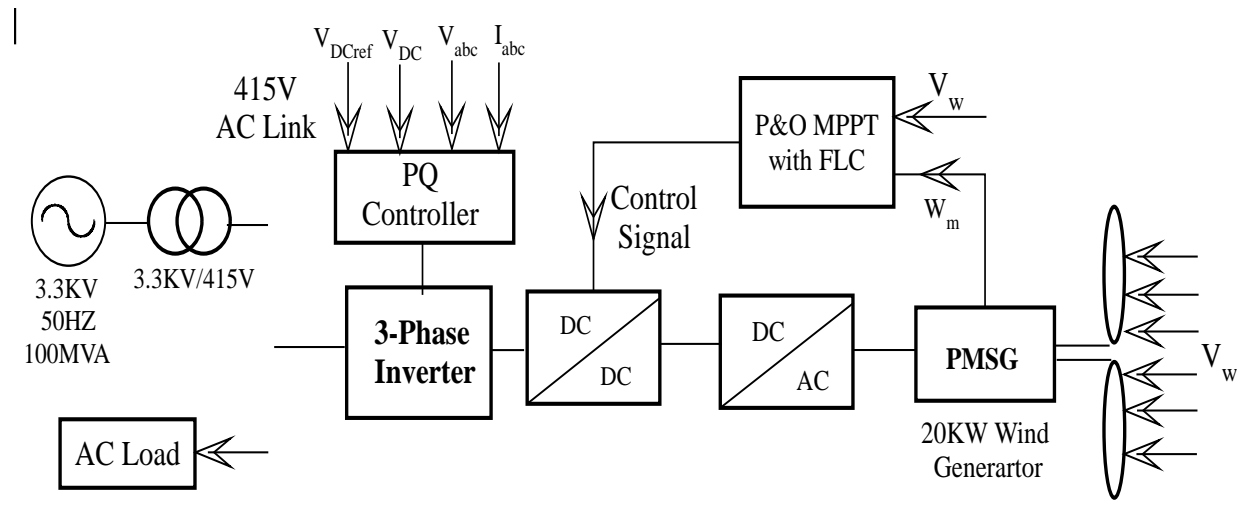

Figure 1. Schematic of grid connected wind energy conversion system

\section{MODELING AND CONTROL STRATEGIES}

In this section, a dynamic model of wind turbine of PMSG based WECS with MPPT controller and PQ controller for sharing appropriate real and reactive power with the utility grid are discussed.

\subsection{Modelling of Wind Turbine}

The wind turbines are used to produce power from wind using generators like PMSG. The PMSG is suitable for renewable energy applications because of its higher efficiency, low maintenance requirement. The amount of power generated in wind system can be calculated using the as shown in 1. The modelling equations of the wind turbine are given in [6]. The available power from the wind turbine is given by (1)

$$
P=\frac{1}{2} \rho A C_{P}(\lambda, \beta) v_{w}^{3}
$$


Where $\mathrm{P}$ is the power $(\mathrm{W}), \rho$ is density of air, $\mathrm{A}$ is swept area of rotor, $\mathrm{V}_{\mathrm{w}}$ is velocity of wind in $\mathrm{m} / \mathrm{s}$, and the coefficient of performance is $\mathrm{Cp}$. The wind velocity and speed of rotor are related by (2)

$$
\lambda=\frac{\omega_{m} R}{v_{w}}
$$

Where $\mathrm{R}$ is the radius of rotor, $\omega_{\mathrm{m}}=$ speed of the rotor in $\mathrm{rad} / \mathrm{sec}, \lambda=$ tip speed ratio (TSR). The relation between the torques of the wind turbine on the shaft and the power is given by the equation

$$
T_{m}=\frac{P_{m}}{\omega_{m}}=\frac{1}{2} \rho \pi R^{5} \frac{\omega_{m}{ }^{3}}{\lambda_{m}{ }^{3}} C_{P}(\lambda, \beta)
$$

The value of $\mathrm{C}_{\mathrm{p}}$ can be evaluated using the relation (3-4)

$$
C_{P}(\lambda, \beta)=0.5176\left(\frac{116}{\lambda_{i}}-0.4 \beta-5\right) e^{\frac{-21}{\lambda_{i}}}
$$

Where

$$
\lambda_{i}=\left[\frac{1}{\lambda+0.08 \beta}-\frac{0.035}{\beta^{3}+1}\right]^{-1}
$$

The MPPT algorithm is used to keep the coefficient of performance $C_{p}$ at its maximum value, $C_{p}=C_{p, \max }$, which is corresponding to $\lambda_{\text {opt }}(5-6)$ [7].

$$
\begin{aligned}
& \omega_{\text {ref }}=\frac{v_{w} \lambda_{\text {opt }}}{R} \\
& P=\frac{1}{2} \rho A C_{P(\max )}\left(\frac{R \omega_{\text {ref }}}{\lambda_{\text {opt }}}\right)^{3}
\end{aligned}
$$

The wind turbine model parameters are reported in Table 1.

Table 1. Wind turbine model parameters [8]

\begin{tabular}{cc}
\hline Parameters & Values \\
\hline Wind turbine blade radius & $3.7 \mathrm{~m}$ \\
Density of air & $1.225 \mathrm{~kg} / \mathrm{m}^{2}$ \\
Number of turbine blades & 3 \\
Power coefficient $C_{\mathrm{p}}$ of wind turbine & 0.46 \\
Rated Wind Speed & $12 \mathrm{~m} / \mathrm{s}$ \\
\hline
\end{tabular}

\subsection{MOOT controller}

The schematic diagram of MPPT with FLC for wind system is shown in Figure 2. A FLC is used to rotate the rotor with the speed corresponding to maximum power point. 


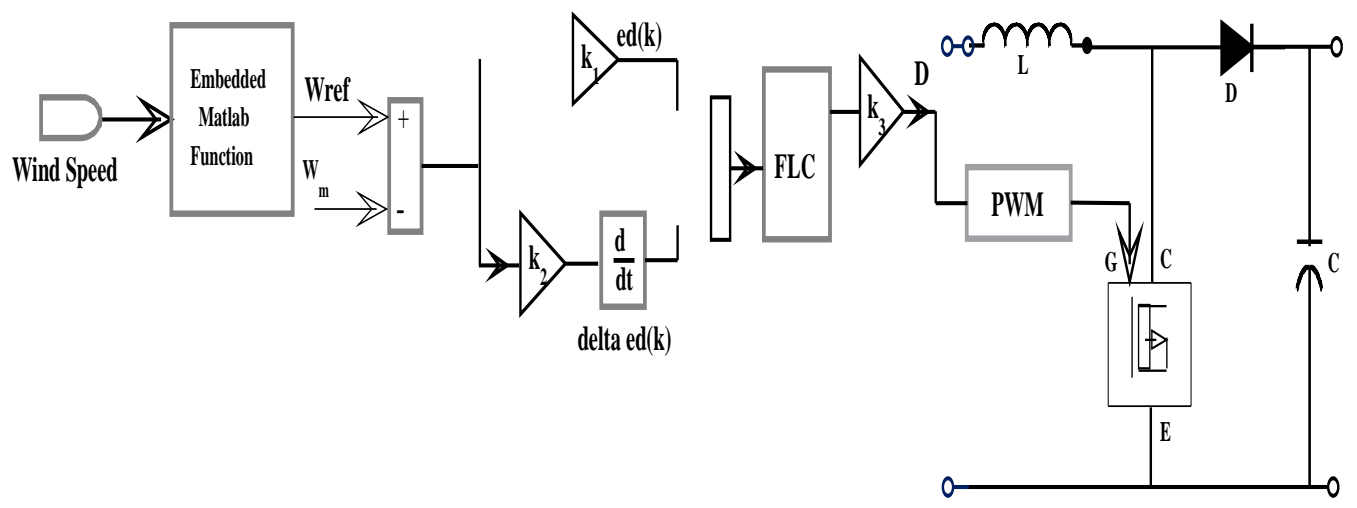

Figure 2. MPPT controller for wind energy system

The triangular membership functions for inputs and output used in FLC are shown in Figure 3 and Figure 4 respectively. The design of a fuzzy controller is detailed in [11, 12]. Mamdani fuzzy inference engine is used with centroid method of de-fuzzification. The input and the corresponding output variables are fuzzified by seven linguistic variables.

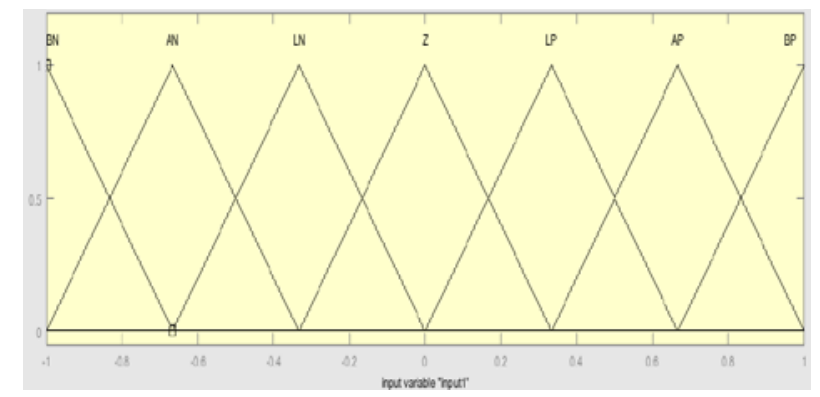

Figure 3. Membership function of inputs (e and $\Delta \mathrm{e})$

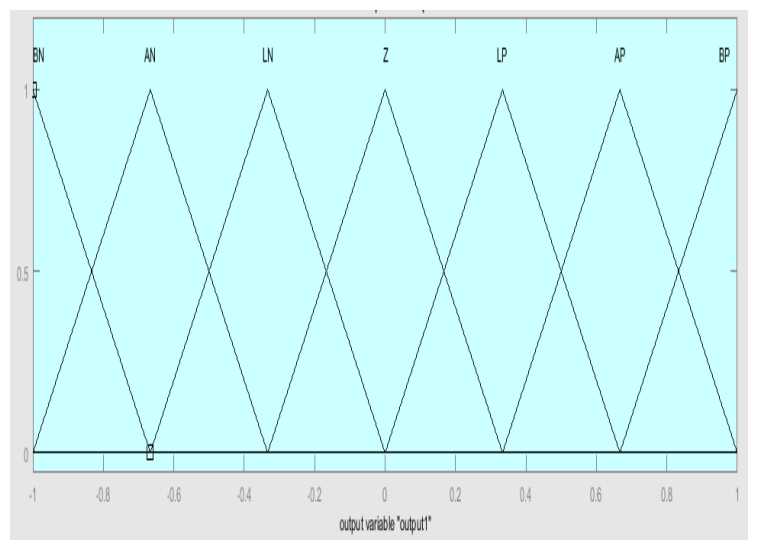

Figure 4. Output membership function

The rule base of FLC where E denotes the error signal and CE represents the change in error signal are shown in Table 2. Seven membership functions namely Big Negative (BN), Average Negative (AN), Lesser Negative (LN), Zero (Z), Lesser Positive (LP), Average Positive (AP), and Big Positive (BP) are used. 
Table 2. Set of rules for FLC [11]

\begin{tabular}{llllllll}
\hline E/CE & BN & AN & LN & Z & LP & AP & BP \\
\hline BN & BP & BP & AP & LN & AN & BN & BN \\
AN & BP & AP & LP & LN & BN & AN & BN \\
LN & AP & LP & LP & Z & LN & LN & BN \\
Z & SN & AN & LN & Z & LP & LP & BP \\
LP & AN & LN & LN & Z & LP & LP & AP \\
AP & BM & AN & LN & LP & LP & MA & BP \\
BP & BN & BN & AN & LP & AP & BP & BP \\
\hline
\end{tabular}

\subsection{Real and reactive power controller}

The grid side inverter is designed in order to maintain the DC bus voltage and power exchange with the utility. The PI controller is used to tune the grid current and grid voltages in $\mathrm{d}-\mathrm{q}$ axis of the synchronous frame. The angle $\theta$ is computed from the system three-phase voltages using the phase-locked loop. The schematic diagram of PQ controller is depicted in Figure 5.

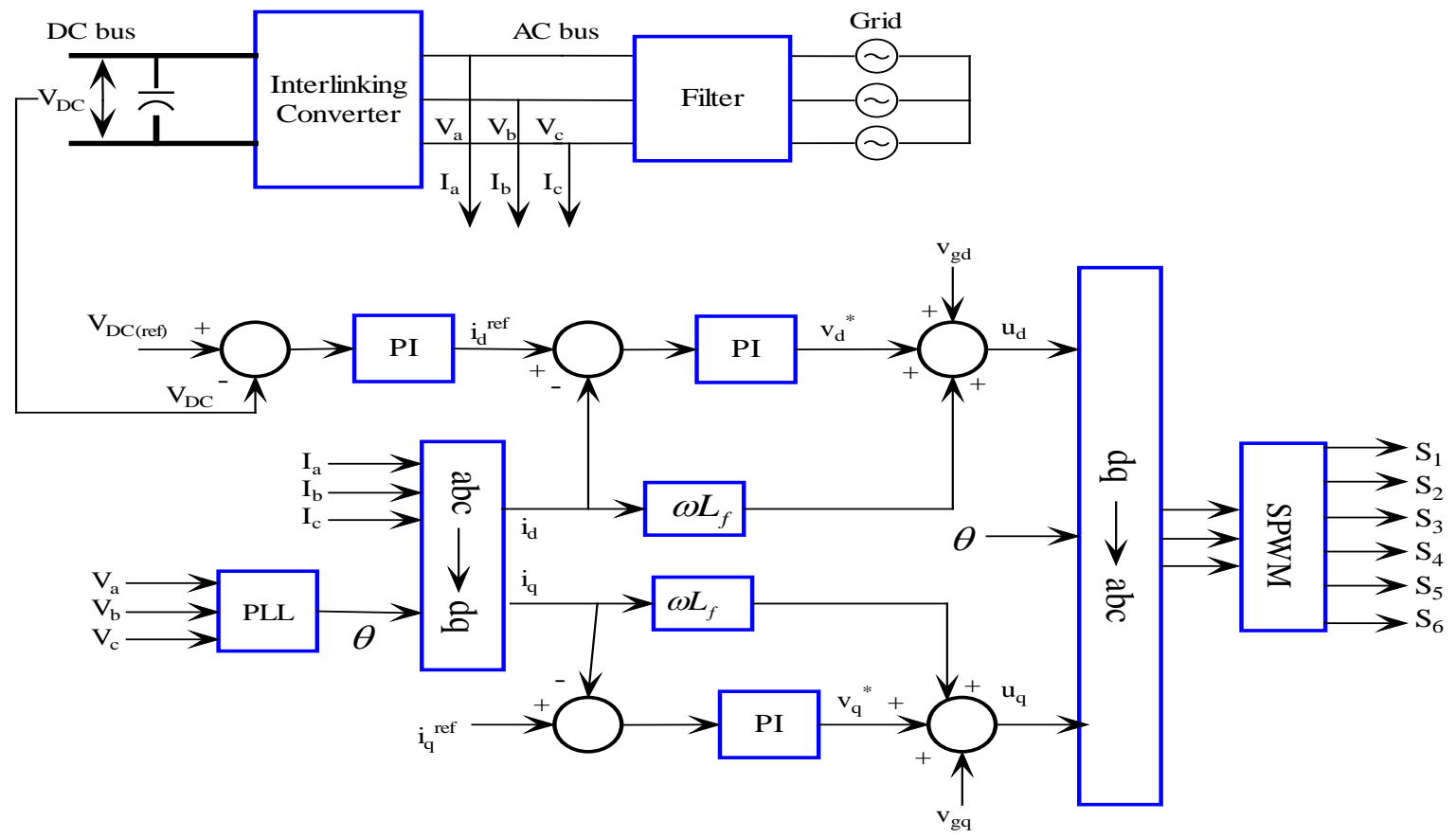

Figure 5. Control Scheme for Grid Side Converter

The active and reactive power sharing with the grid can be controlled by regulating the direct and quadrature axis currents respectively. There are two control loops in the control system, one is the outer control loop which maintains DC link voltage of $800 \mathrm{~V}$ and an inner loop which controls direct and quadrature axis currents. The control signal obtained from the outer control loop is used to set the reference current of d-axis for controlling the injected active power. The current reference corresponding to q-axis is set to be zero [8], so that the reactive power injected to the utility grid is zero.

\section{RESULTS AND DISCUSSION}

The performance of the system is analysed for three different cases. The power versus rotor speed and power coefficient versus TSR characteristics of the wind turbine are shown in Figure 6 and Figure 7 respectively. 


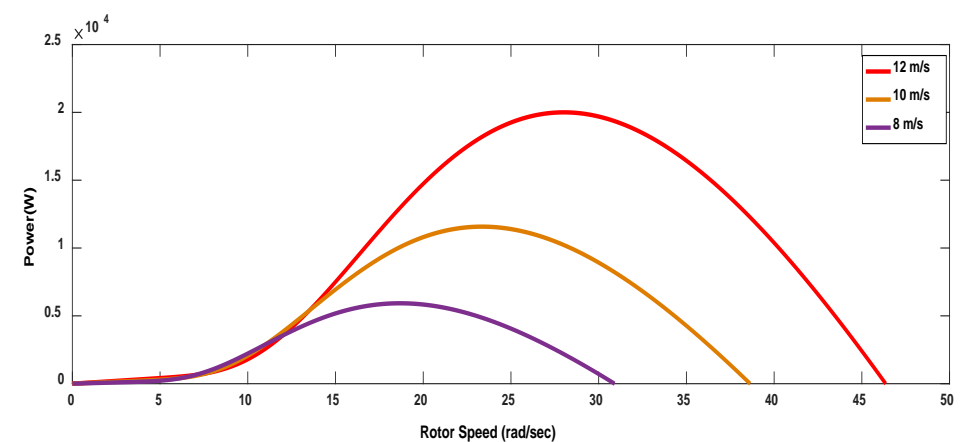

Figure 6. Typical power vs rotor speed characteristics of a wind turbine

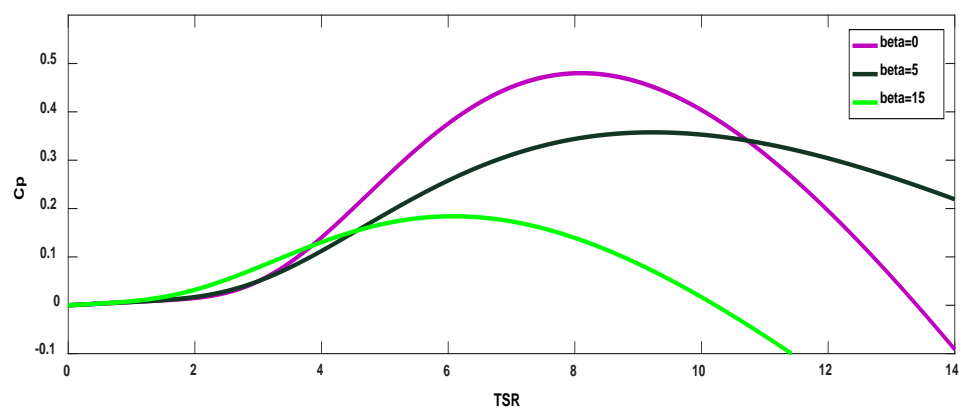

Figure7. Typical curves for Power coefficient versus TSR

Case A: Performance analysis of FLC and PID controller

In this case, the performance of wind energy system is analysed under varying system parameters using both PID controller and fuzzy logic controller. The results obtained from PID controllerand FLC are compared.

\subsection{PID Controller}

The variable wind velocity input considered for the WECS is reported in Figure 8 and Figure 9 shows the power output of the WECS for given variable input and a constant load for 10 seconds. Figure 10 shows the error between reference speed and actual speed of the rotor. It can be seen that the error fluctuation is more for varying system conditions. The DC link voltage. The inverter control strategy effectively maintains the DC link voltage at $800 \mathrm{~V}$ as depicted in Figure 11. Figure 12 shows the reactive power exchanged between wind system and grid. Since the reference current corresponding to q-axis is considered as zero in PQ controller there is no reactive power exchange.

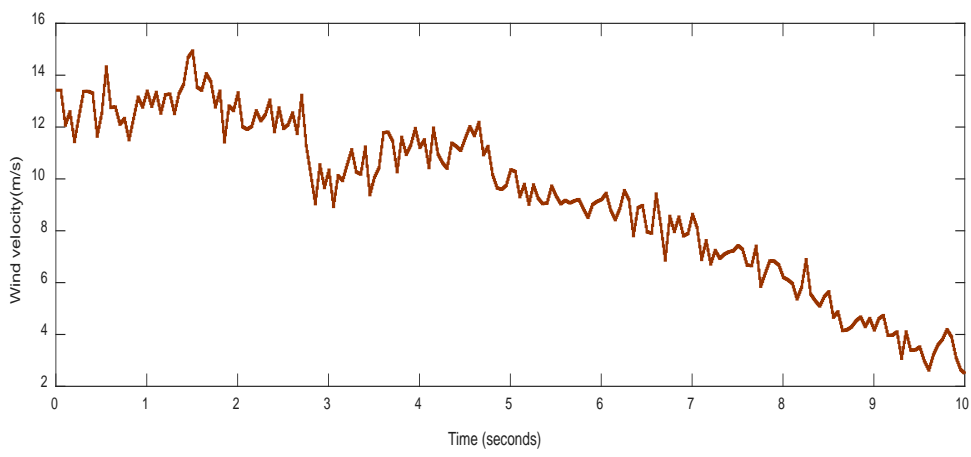

Figure 8. Wind velocity 


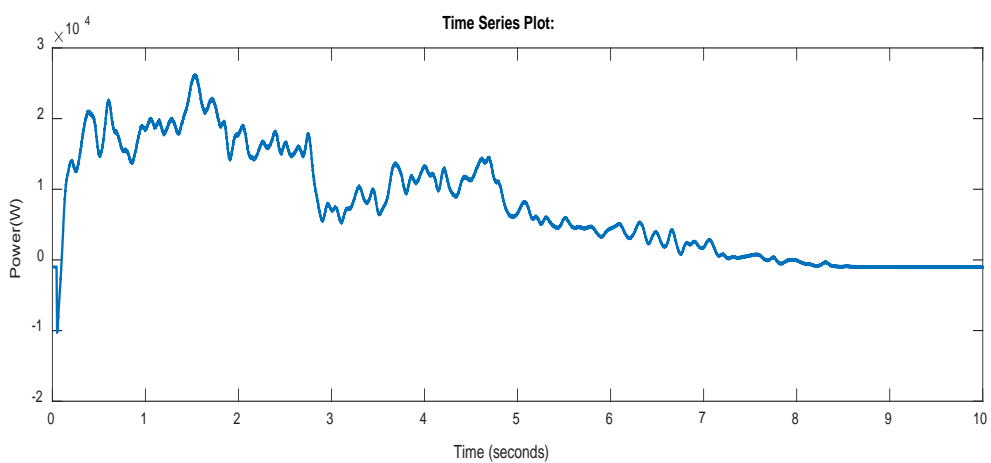

Figure 9. Output power of wind turbine

Provide a statement that what is expected, as stated in the "Introduction" chapter can ultimately result in "Results and Discussion" chapter, so there is compatibility. Moreover, it can also be added the prospect of the development of research results and application prospects of further studies into the next (based on result and discussion).

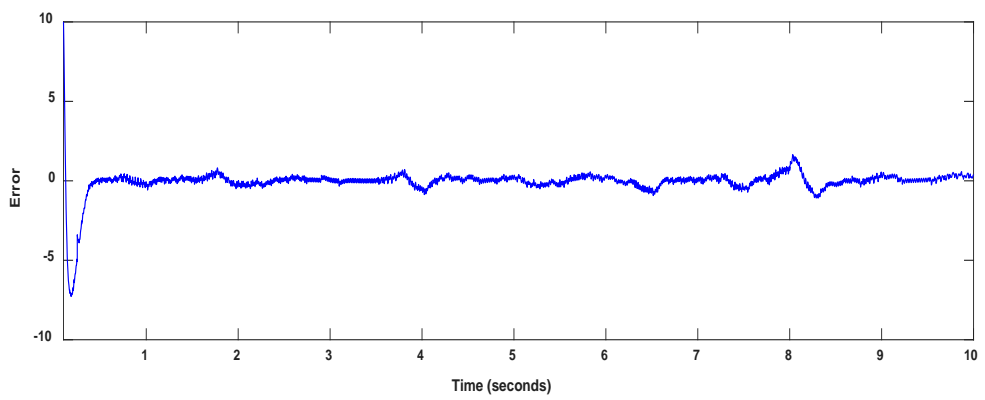

Figure 10. Difference between reference speed generated and actual speed of the rotor with PID controller

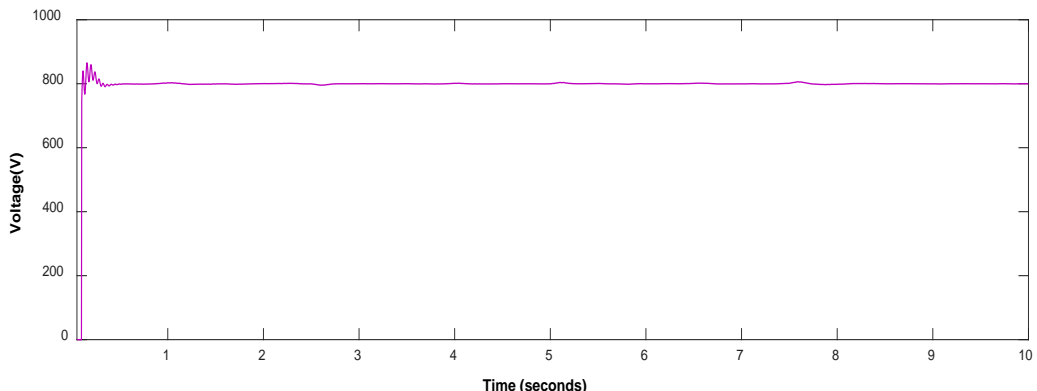

Figure 11. DC link Voltage

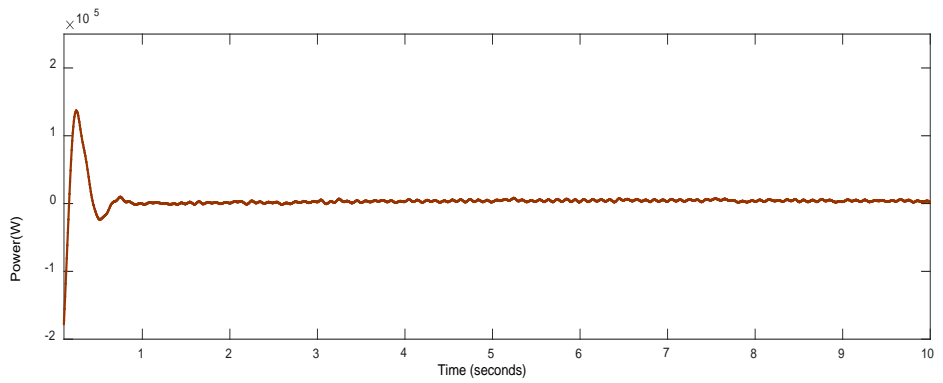

Figure 12. Reactive power exchange 


\subsection{Fuzzy Logic Controller}

The power output of the WECS for given variable input and a constant load is shown in Figure 13. Figure 14 shows the error between reference speed and actual speed of the rotor. From Figure 8 and Figure 13, we can see that the power output of boost converter is higher with FLC based MPPT as compared to PID controller. Also it is evident from Figure 10 and Figure 14 that the fluctuations in the error signal between actual and reference speed are reduced with FLC as compared to PID controller. The Fuzzy logic algorithm successfully tracking the MPPs and performs precise control under rapidly changing atmospheric conditions and FLC is considered for analysis of WECS in case B and C.

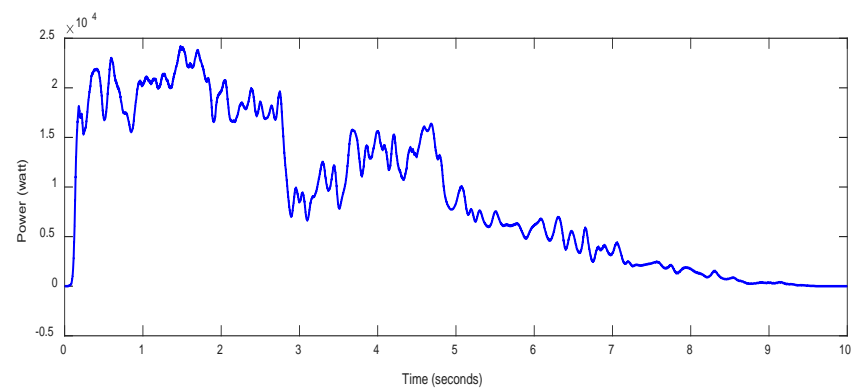

Figure 13. Output power of wind turbine with FLC based MPPT

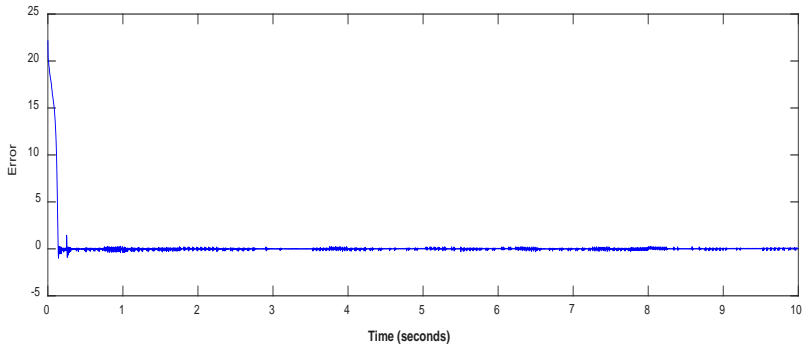

Figure 14. Difference between reference speed generated and actual speed of the rotor with FLC

Case B: Constant Velocity with Varying Load

In this case, a constant wind velocity of $10 \mathrm{~m} / \mathrm{s}$ is considered as an input to the WECS. Figure 15 (a) shows the power output of WECS for given input and the output power is $12.11 \mathrm{~kW}$. The error between reference speed generated by MPPT algorithm and the actual speed of rotor is shown in Figure 15 (b). Figure 15 (c) shows the regulated DC link voltage. Figure 15 (d) shows the reactive power exchanged between wind system and grid. The grid side voltage. It is observed that the three-phase voltage is less distorted sine wave at the grid side is demonstrated in Figure 15 (e). The current supplied to the grid is depicted in Figure 15 (f) and Figure 15 (g) shows the harmonic spectrum of the current supplied to the grid. As per IEEE standards, total harmonic distortion should be below 5 percent and it is found to be 4.44 percent which is in the acceptable limits.

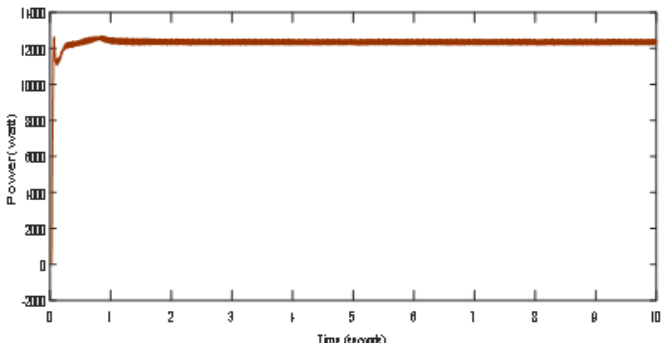

(a)

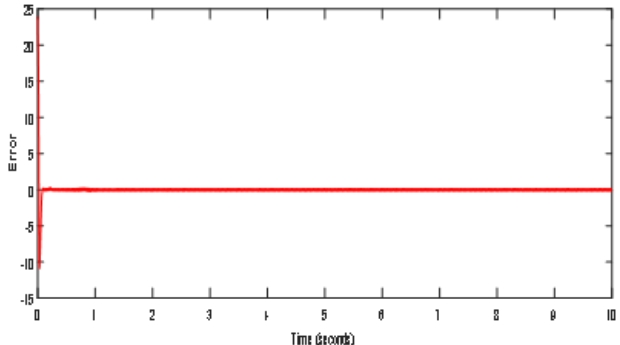

(b)

Figure 15. (a) Output power of wind turbine, (b) Error signal 


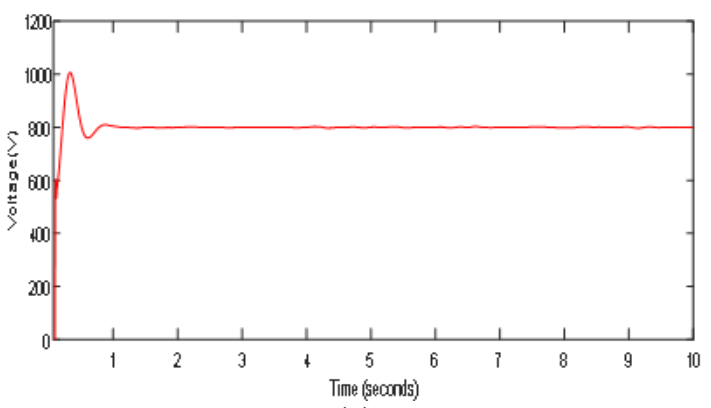

(c)

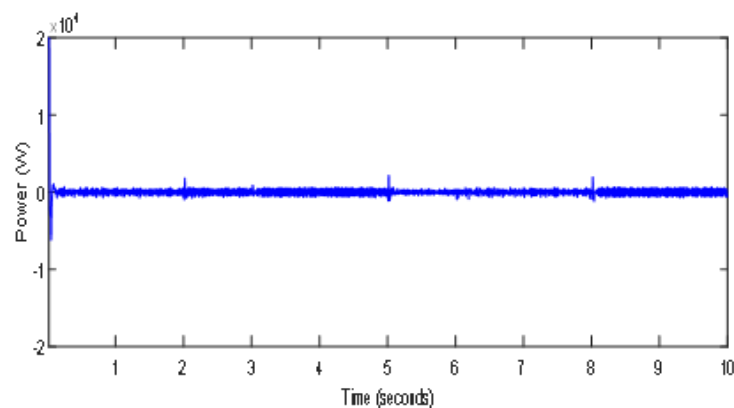

(d)

Figure 15. (c) DC link Voltage, (d) Reactive power

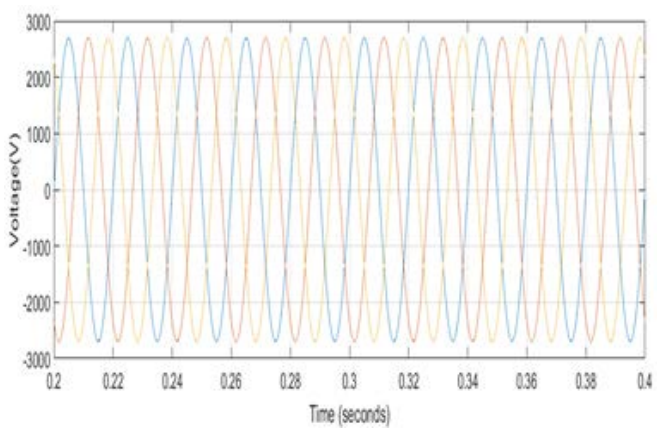

(e)

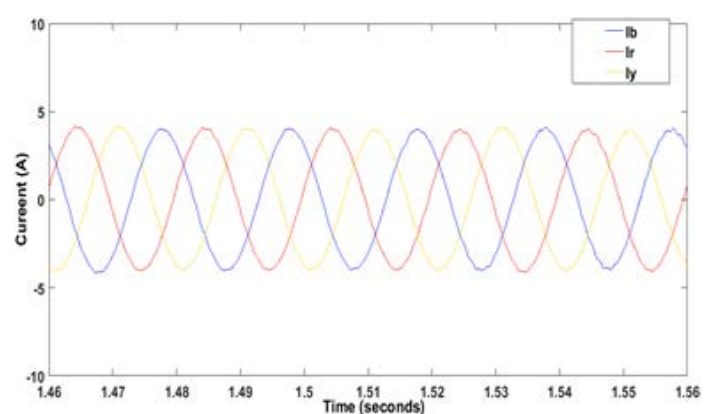

(f)

Figure 15. (e) Grid side voltage, (f) Current supplied to the grid

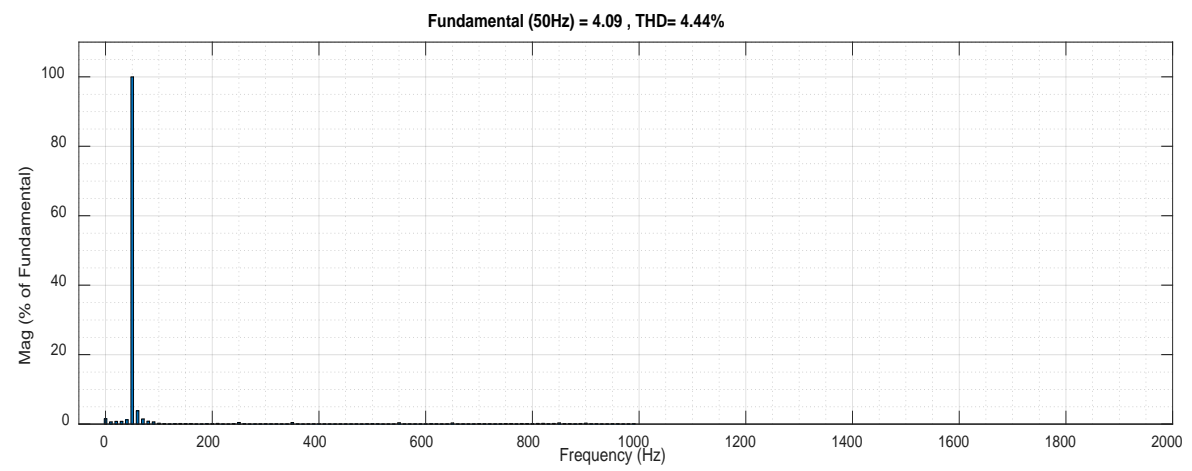

Figure 15. (g) Harmonic spectrum of grid current

Case C: Variable wind velocity with variable Load

The variable wind velocity input to the WECS and the corresponding power output of the WECS for variable velocity input are reported in Figure 16 (a) and Figure 16 (b). Figure 16 (c) shows the error between reference speeds of the rotor. The DC link voltage is reported in Figure 16 (d). The inverter control strategy effectively regulates the DC link voltage under sudden source and load variations. The variation in DC voltage is found to be less than 4 percent of the reference value. Figure 16 (e) shows the varying load demand connected to the grid connected WECS. The reactive power exchanged between wind system and grid is reported in Figure 16 (f). 


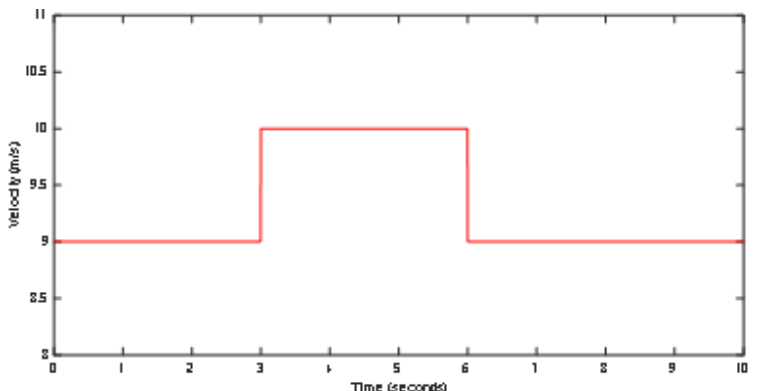

(a)

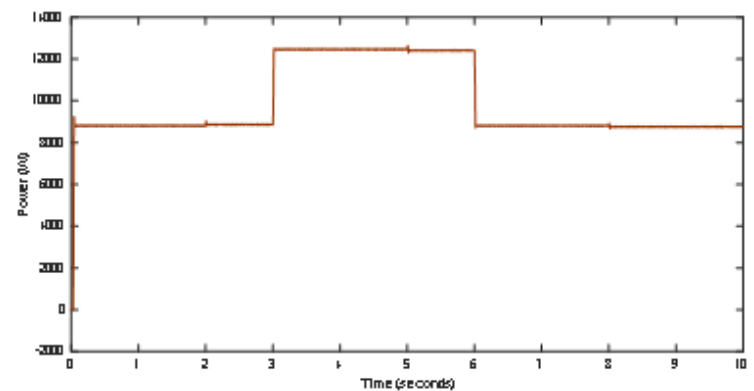

(b)

Figure 16. (a) Wind velocity, (b) Output power of wind turbine

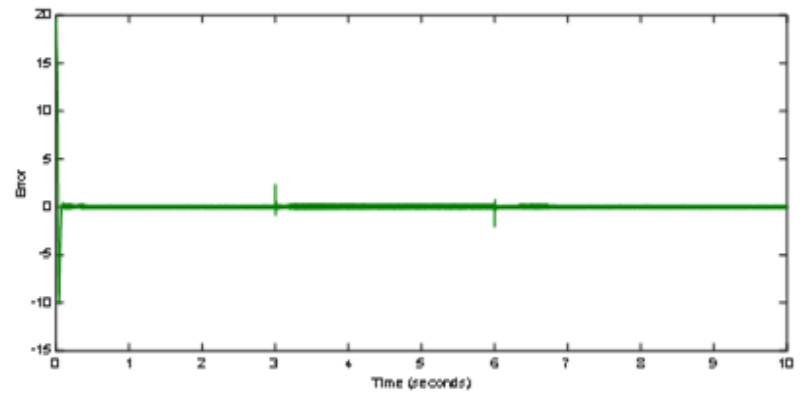

(c)

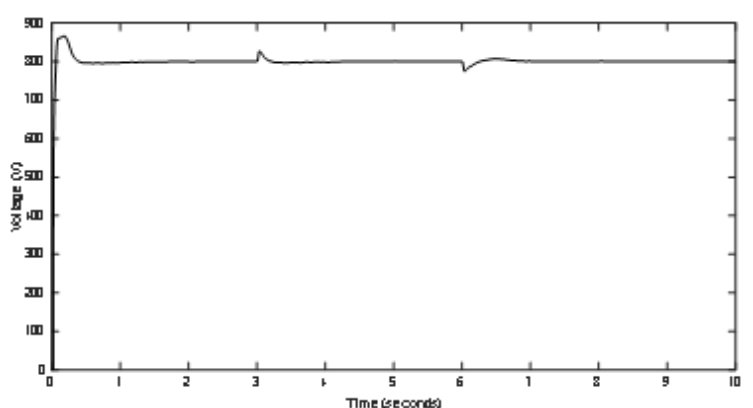

(d)

Figure 16. (c) Error with FLC, (d) DC link Voltage

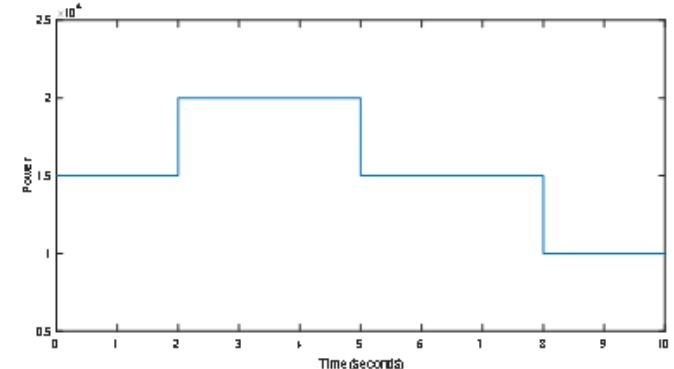

(e)

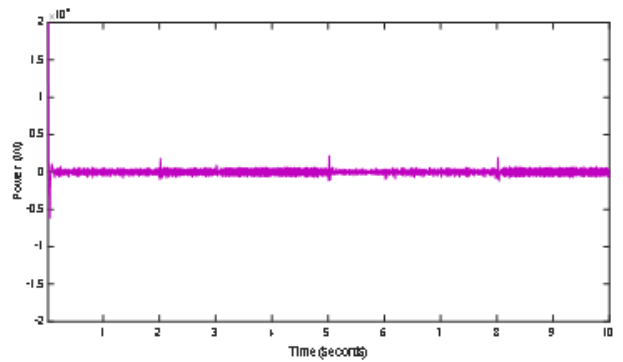

(f)

Figure 16. (e) Load demand, (f) Reactive power

\section{CONCLUSION}

A grid tied WECS is simulated in MATLAB/Simulink software. A comparative study of PID and FLC based MPPT controller is performed and it is concluded that FLC performs better than PID controller. A PQ controller is realized for effective power sharing between WECS and utility grid. The system performance is analysed both under varying source and load conditions. In the grid tied WECS, the DC link voltage is maintained at $800 \mathrm{~V}$ and reactive power injected to the utility grid is zero. The total harmonic distortion of grid current is found to be within acceptable limit as per IEEE standards. Thus a grid integrated wind system with an efficient MPPT technique is realized without compromising the quality of power.

\section{REFERENCES}

[1] http://www.gwec.net/wpcontent/uploads/vip/GWECPRstats 2016_EN_WEB.pdf.

[2] Weiliang Liu, Lei Chjen, Jing Ou, and Shukang Cheng, "Simulation of PMSG wind turbine system with sensor-less control technology based on model reference adaptive system”, International Conference on Electrical Machines and Systems, Beijing, Aug 2011, pp.1-3. 
[3] Monica chinchilla, Santiago Arnalites and Juan Carlos Burgos, "Control of permanent generators applied to a variable-speed wind-energy systems connected to the grid”, IEEE Trans on Energy Converstion, vol. 21, no.1, Mar 2006, pp.130-135.

[4] AsmaTounsi , HafedhAbid, Maher Kharrat and KhaledElleuch, "MPPT algorithm for wind energy conversion system based on PMSG" ,International conference on Sciences and Techniques of Automatic control \& computer engineering, Monastir, Tunisia, December 2017.

[5] Zakariya M. Dalala, ZakaUllahZahid, WensongYu,YounghoonChoandJih-Sheng (Jason) Lai, "Design and Analysis of an MPPT Technique for Small-Scale Wind Energy Conversion Systems”, IEEE Transactions on Energy Conversion, vol. 28, no. 3, Sep 2013,pp.756-767.

[6] A. Rolan, A. Luna, G. Vazquez, A.Daniel, A.Gustavo, "Modelling of a Variable Speed Wind Turbine with a Permanent Magnet Synchronous Generator” Proceedings of IEEE Proceedings of IEEE International Symposium on Industrial Electronics ISIE, 2009, pp. 734-739.

[7] A. Khazaee, H.A. Zarchih, M. Ebrahimi "Robust Maximum Power Point Tracking Control of Permanent Magnet Synchronous Generator for Grid Connected Wind Turbines”, 2nd Iranian Conference on Renewable Energy and Distributed Generation (ICREDG), 2012,pp. 75 - 79.

[8] Jayalakshmi N. S. and D. N. Gaonkar, "Maximum Power Point Tracking for Grid Integrated Variable Speed Wind based Distributed Generation System with Dynamic Load”, International Journal of Renewable Energy Research, Vol. 4, No. 2, 2014.

[9] Saleh A and M. Saleh, "Testing the Performance of a Resolution-Level MPPT Controller for PMG-Based Wind Energy Conversion Systems”, IEEE Transactions on Industry application, Vol. 53, NO. 3, May/June2017, pp. 2526-2540.

[10] TukaramMoger, and ThukaramDhadbanjan, "Fuzzy logic approach for reactive power coordination in grid connected wind farms to improve steady state voltage stability”, IET Renewable Power Generation., vol. 11 Iss. 2, pp. 351-361, 2017.

[11] Abdul-Rahman, K., Shahidehpour, S. 'A fuzzy-based optimal reactive power control', IEEE Trans. Power Syst., 1993, 8, (2), pp. 662-670.

[12] S. M. Muyeen and Ahmed Al-Durra, "Modeling and Control Strategies of Fuzzy Logic Controlled Inverter System for Grid Interconnected Variable Speed Wind Generator”, IEEE Systems journal, Vol. 7, no. 4, pp. 817-824, December 2013.

[13] E. H. Watanabe, J. L. Afonso, L. F. C. Monteiro, and H. Akagi, "Instantaneous p-q Power Theory for Control of Compensators in Micro-Grids", International School on Nonsinusoidal Currents and Compensation, pp.17-25, June 15, 2010

[14] Abdullah S. Bubshait, Ali Mortezaei, Marcelo Godoy Simoes and Tiago DaviCuriBusarello, "Power Quality Enhancement for a Grid Connected Wind Turbine Energy System”, IEEE transactions on industry applications, Vol. 53, no. 3, pp. 2495-2505, 2017.

[15] L. Gidwani, H.P. Tiwari, R.C. Bansal, N.Mithulananthan, "Improving Power Quality of Wind Energy Conversion System with Efficient Power Electronic Interface”, International Journal of Electrical Power and Energy Systems, Elsevier Publications, 01/2013; 44(1):445-453.

\section{BIOGRAPHIES OF AUTHORS}
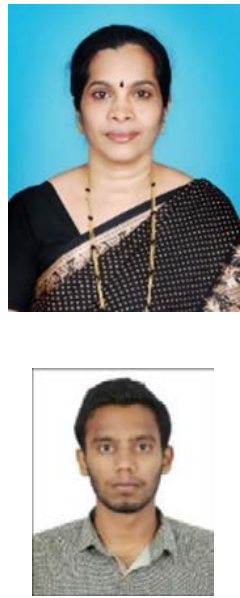

She has obtained B.E. degree in Electrical Engineering from M.S.R.I.T., Bangalore, India and M. Tech. in Power Systems from National Institute of Engineering, Mysore, India in 1991 and 1999 respectively.She received her $\mathrm{Ph}$. D. degree from the Department of Electrical and Electronics Engineering, National Institute of Technology, Karnataka, Surathkal, India. Presently, she is working as Professor in the Department of Electrical and Electronics Engineering, Manipal Institute of Technology, Manipal Academy of Higher Education, Manipal, India. She has published many papers in international journals and conferences. Her research areas include PV, fuel cell and wind based distributed generation systems, modeling and control of microgrid

Sachin S. is a M. Tech. student of Power Electronics and Drives in the Department of Electrical and Electronics Engineering, MIT, Manipal Academy of Higher Education, Manipal, India576104. His research areas of interest are distributed generations, power electronics and control. 